\title{
Normalization and Reliability Evaluation of Persian Version of Two-Pair Dichotic Digits in 8 to 12-Year-Old Children
}

\author{
Mitra Rezapour ${ }^{1}$, Farzaneh Zamiri Abdollahi²*, Maryam Delphi ${ }^{3}$, Yones Lotfi ${ }^{2}$, Enayat-Allah Bakhshi² \\ 1. Department of Audiology, Iran University of Medical Sciences, Tehran, Iran. \\ 2. Department of Audiology, University of Social Welfare and Rehabilitation Sciences, Tehran, Iran. \\ 3. Musculoskeletal Rehabilitation Research Center, Ahvaz Jundishapur University of Medical Sciences, Ahvaz, Iran.
}

Citation: Rezapour M, Zamiri Abdollahi F, Delphi M, Lotfi Y, Bakhshi E.A. Normalization and Reliability Evaluation of Persian Version of TwoPair Dichotic Digits in 8 to 12-Year-Old Children. Iranian Rehabilitation Journal. 2016; 14(2):115-120. https://doi.org/10.18869/nrip.irj.14.2.115

: https://doi.org/10.18869/nrip.irj.14.2.115

Article info:

Received: 08 Jan. 2016

Accepted: 29 Apr. 2016

\section{Keywords:}

Two-pair dichotic digits test, Dichotic hearing processing, Free recall paradigm

\section{ABSTRACT}

Objectives: All subjects suspected of Central Auditory Processing Disorder (CAPD) were previously tested by free recall dichotic digits test (DDT). The study objective was normalization and reliability evaluation of two-pair DDT in 750 native Persian subjects aged 8 to 12 years.

Materials: A total of 750 subjects were divided into five age groups varying between 8 years and 12 years and 11 months old. Each age group had 150 subjects. DDT was tested in free recall condition. For evaluating DDT test-retest reliability, 300 participants (60 subjects in each age group) were tested again after one month.

Results: Right and left ear mean score increased from 71.68( \pm 2.19$)$ and $58.51( \pm 1.71)$ in the 8-year-old group to $90.26( \pm 1.96)$ and $88.38( \pm 1.36)$ in 12-year-old group, respectively. The mean Right Ear Advantage (REA) decreased from 13.16( \pm 2.58$)$ in the 8-year-old group to $1.88( \pm 2.49)$ in the 12-year-old group. A high stability was observed between test-retest results $(\mathrm{P}<0.0001)$.

Discussion: Persian version of two-pair dichotic digits exhibited proper reliability for evaluating 8 to 12-year-old subjects, and the study results can be used for evaluating the dichotic hearing function in subjects of the same age group.

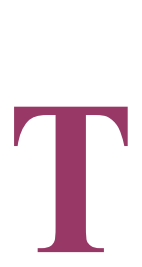

\section{Introduction}

he auditory function of each ear is usually assessed individually, but listening in everyday activities is a binaural function. Therefore, auditory system must integrate the competing information coming from two ears in a quicker way [1]. Subjects with normal peripheral hearing, who complain about listening difficulties in noisy or competing environments, suffer from Central Auditory Processing Disorder (CAPD), which accounts for 2-3\% of children. Children with CAPD report certain types of hearing difficulties at school. For example, they report uncertainty about what they have heard, listening difficulties in a noisy environment, understanding and following oral instructions or difficulty in understanding fast or degraded speech. Therefore, for accurate auditory

* Corresponding Author:

Farzaneh Zamiri Abdollahi, PhD Candidate

Address: Department of Audiology, University of Social Welfare and Rehabilitation Sciences, Koodakyar Ave., Daneshjoo Blvd., Evin, Tehran, Iran. Tel: +98 (21) 22180100

E-mail:audiology_zamiri@yahoo.com 
function evaluations, especially in noisy environments, dichotic hearing tests are necessary [2-4].

Dichotic hearing is a condition in which different auditory stimuli are presented simultaneously to each ear. A variety of stimuli can be used including syllables, digits, words or sentences. From the introduction of dichotic digit test (DDT) by Broadbent (1954) and its' modifications by Kimura (1961) and Bryden (1963), digits have been proven to be effective stimuli for auditory processing assessment $[1,5,6]$. In addition, ASHA (1996) declared dichotic digits as the most suitable dichotic stimuli for CAPD evaluation. DDT exhibits some relevant characteristics that make it suitable for evaluation of children with hearing difficulties. These characteristics include high sensitivity, fast (less than 5 minutes) and easy to perform, fast scoring, little linguistic load, easy to understand test instructions and respond accordingly, unbiased toward mild conductive/sensorineural hearing loss, and compatible with different response techniques like pointing to the correct numbers or writing them down $[7,8]$.

Nowadays, one-pair and two-pair DDT are available for clinical evaluation of CAPD. In one-pair DDT, the hearing impaired patients can score a $100 \%$ like that of the normal subjects. But, the two-pair DDT is considered to be the best dichotic test because it is easier to test on children. However, it is more complex and challenging for analysis of the auditory system compared to the one-pair DDT [9-11]. In 2000, it was recommended that all subjects with suspected APD should be tested with two-pair DDT due to the higher prevalence of dichotic auditory disorders [2]. Dichotic tests can also be used for evaluating central auditory maturation and determining hemispheric language dominance in both children and adults. In DDTs, free recall condition is generally used (i.e. to repeat all digits heard regardless of ear or digit order). Test interpretation is based on right and left ear score and ear advantage (score difference between the two ears).

In children, right ear score is usually higher than the left ear, and the left brain hemisphere is language dominant. This phenomenon is called Right Ear Advantage (REA). In most of the dichotic hearing tests, the auditory system maturation improves both ears' score over time. However, left ear score improvement is generally faster and larger than the right ear, and this leads to a progressive reduction in REA. In 11-12-year-old children, REA is similar to hat of the adults [11-15].

One of the criteria for CAPD diagnosis is higher REA and low left ear score. These findings show late maturation or CAPD. Reverse ear advantage (i.e. left ear advantage) is common among learning disabled (LD) children. Left Ear Advantage (LEA) is a sign of left brain hemisphere impairment [11]. For diagnostic purposes, there is an urgent need for having DDT normative data for different age ranges as DDT score changes with age. The DDT normative data for different age groups can enable us to follow up dichotic hearing maturation process in children and differentiate between late maturation and CAPD. In late maturation, the subjects' score improves over time, but this does not happen for the subjects with CAPD [7, 11]. For DDT, every language must have stimuli of their own and find normative data [7]. The aim of the present study is to obtain normative data and determine the test-retest reliability of the Persian version of two-pair DDT using free recall condition.

\section{Methods}

This study was conducted on 750 normal hearing children including 250 males and 500 females aged 8-12 years (150 subjects in each age group). Subjects were selected from the students of five selected elementary schools in Karaj. Written consent was obtained from the parents before starting the research work. The research process and tests were explained thoroughly to them. The demographic information and medical history were recorded. Exclusion criteria were ear diseases, abnormal peripheral auditory function, speech and language disorders, neurological disorders (especially epilepsy), meningitis, head trauma, math and/or writing and/or reading problems based on the teachers' report.

All subjects had normal IQ (95 or higher) based on Wechsler IQ test, were right-handed (based on Edinburgh test) and monolingual (native Persian speakers). For evaluating the peripheral auditory system, the techniques like autoscopy, immittance audiometry by Madsen Zodiac 901 and pure tone and speech audiometry including speech recognition threshold (SRT) and word recognition score (WRS) by Clinical Audiometer AC 33 were used. The normal peripheral auditory function was determined based on normal autoscopy, tympanogram, with normal hearing criteria like pure-tone average (PTA) $\leq 20 \mathrm{~dB}$ HL at six varied octave frequencies from 250 to $8000 \mathrm{~Hz}$, hearing threshold asymmetry $\leq 5 \mathrm{~dB}$, word recognition scores (WRS) in quiet $\geq 90 \%$.

DDT was conducted in an acoustic chamber at Akhavan rehabilitation center related to the University of Social Welfare and Rehabilitation Sciences. The test consisted of digits from 1 to 10 except for number 4 that is two syllabic in the Persian language. Test intensity level was $50 \mathrm{~dB}$ SL re SRT. Four numbers were presented to two ears simultaneously (two numbers to each ear), and 
the subjects had to repeat all numbers regardless of ear or digit order. Twenty pairs of digits (40 digits) were presented to each ear. Total score for both the ears and for each ear individually was recorded. Ear advantage score was calculated by subtracting left ear score from the right ear score. Before the test, some exercise trials were used [16]. For presenting stimuli, Sony Mp3 player NWZ-B162F was connected to clinical audiometer, and the stimuli were presented via TDH-39 headphone.

For determining DDT test-retest reliability, first 60 subjects of each age group were selected (300 subjects in all), and DDT was repeated after one month.

For data analysis, SPSS version 16 (IBM Corp., IL, USA) was used and descriptive information such as mean values and standard deviations were extracted. Paired t test was used for comparing mean score between two ears, and one-way ANOVA test was used for comparing mean REA among different age groups. For evaluating gender effect on DDT score, independent $t$ test was used. For test-retest reliability estimation, Pearson correlation coefficient and paired t test were calculated. Statistical significance level was set at 0.05 .

\section{Results}

In the present study, we included 750 children in the age groups of 8 to 12 years ( 250 males and 500 females). There were five age groups ( 150 children in each group): 8 years to 8 years and 11 months old, 9 years to 9 years and 11 months old, 10 years to 10 years and 11 months old, 11 years to 11 years and 11 months old, and 12 years to 12 years and 11 months old.

DDT score mean value and standard deviation for right and left ears and each age group are summarized in Table 1. Ear advantage mean value and SD (percent) in the five age groups are shown in Table 2. As you can see, in all age groups, right ear score was higher than that of left ear.

The right and left ear DDT score in all age groups showed significant difference based on paired test $(\mathrm{P} \leq 0.001)$ while the right ear score was significantly higher. Based on the ANOVA and post hoc analysis, REA showed a significant difference between all age groups $(\mathrm{P} \leq 0.001)$. The independent $t$ test showed that gender had no effect on two-pair DDT $(\mathrm{P} \geq 0.005)$.

The DDT retest in 300 children after one month showed a correlation coefficient of 0.99 . Persian version of twopair DDT showed high test-retest reliability. In addition, the paired $t$ test showed no significant statistical difference between the mean DDT score value in test and re-test conditions $(\mathrm{P} \geq 0.005)$. The results are summarized in Table 3 .

\section{Discussion}

In the present study, REA was obvious in all age groups. The results suggest the dominance of left-brain hemisphere in language processing [11]. Other studies showed that REA was common in right-handed subjects, and only 15 to $20 \%$ had LEA or non-ear advantage (NEA) [17].

Table 1. DDT score mean value and standard deviation (\%) for right and left ears and each age group.

\begin{tabular}{lcccccc}
\hline & & $\begin{array}{c}\text { First Age } \\
\text { Group }\end{array}$ & $\begin{array}{c}\text { Second Age } \\
\text { Group }\end{array}$ & $\begin{array}{c}\text { Third Age } \\
\text { Group }\end{array}$ & $\begin{array}{c}\text { Forth Age } \\
\text { Group }\end{array}$ & $\begin{array}{c}\text { Fifth Age } \\
\text { Group }\end{array}$ \\
\hline \multirow{2}{*}{ Right ear score } & Mean & 71.68 & 77.44 & 82.90 & 88.76 & 90.26 \\
& SD & 2.19 & 1.78 & 1.32 & 1.91 & 1.96 \\
Left ear score & Mean & 58.51 & 73.01 & 76.96 & 85.95 & 88.38 \\
& SD & 1.71 & 2.17 & 2.17 & 2.23 & 1.36 \\
\hline
\end{tabular}

Table 2. Ear advantage mean value and SD (\%) in 5 age groups.

\begin{tabular}{ccccccc}
\hline & & $\begin{array}{c}\text { First Age } \\
\text { Group }\end{array}$ & $\begin{array}{c}\text { Second Age } \\
\text { Group }\end{array}$ & $\begin{array}{c}\text { Third Age } \\
\text { Group }\end{array}$ & $\begin{array}{c}\text { Forth Age } \\
\text { Group }\end{array}$ & $\begin{array}{c}\text { Fifth Age } \\
\text { Group }\end{array}$ \\
\hline \multirow{2}{*}{ REA } & Mean & 13.16 & 4.43 & 5.93 & 2.81 & 1.88 \\
& SD & 2.58 & 2.88 & 2.46 & 2.44 & 2.49 \\
\hline
\end{tabular}


Table 3. Two-pair DDT test re-test reliability in different age groups.

\begin{tabular}{|c|c|c|c|c|c|}
\hline & & \multicolumn{2}{|c|}{ Mean (SD) } & \multirow{2}{*}{$\begin{array}{l}\text { Pearson Correlation } \\
\text { (p-value) }\end{array}$} & \multirow{2}{*}{$\begin{array}{l}\text { Paired t-test } \\
\text { (p-value) }\end{array}$} \\
\hline & & Test & Retest & & \\
\hline \multirow{5}{*}{ Right ear score } & 1st Age group & 71.87 (2.37) & $71.66(2.37)$ & $0.90(\leq 0.001)$ & 0.13 \\
\hline & 2nd Age group & 77.54 (1.62) & 77.62 (1.68) & $0.92(\leq 0.001)$ & 0.32 \\
\hline & 3rd Age group & $83.12(1.63)$ & $83.20(1.60)$ & $0.88(\leq 0.001)$ & 0.41 \\
\hline & 4th Age group & $88.20(2.06)$ & $88.33(2.23)$ & $0.94(\leq 0.001)$ & 0.18 \\
\hline & 5th Age group & $90.41(1.67)$ & $90.54(1.60)$ & $0.90(\leq 0.001)$ & 0.18 \\
\hline \multirow{5}{*}{ Left ear score } & 1st Age group & $58.41(2.05)$ & $58.50(1.96)$ & $0.89(\leq 0.001)$ & 0.48 \\
\hline & 2nd Age group & 72.78 (1.39) & 72.86 (1.29) & $0.88(\leq 0.001)$ & 0.32 \\
\hline & 3rd Age group & 77.25 (2.50) & 77.45 (2.49) & $0.84(\leq 0.001)$ & 0.25 \\
\hline & 4th Age group & $84.29(2.01)$ & $84.16(2.14)$ & $0.91(\leq 0.001)$ & 0.26 \\
\hline & 5th Age group & $88.91(1.40)$ & 88.79 (1.49) & $0.87(\leq 0.001)$ & 0.18 \\
\hline
\end{tabular}

The present study showed increased DDT score in both the ears with age, but this growth was faster for left ear; therefore, REA was seen to reduce with age. The present findings are in agreement with other researches. Similar results were also presented by Pohl et al. (1984) in the case of 4 to 10 -years-old children. The reason for DDT score improvement is the maturation of interconnections between the two brain hemispheres over time [12]. Mukari et al. (2006) made Malay version of one and two-pair DDT and found normative data in 120 normal hearing children aged 6-11 years old, for free recall and directed attention condition. In free recall condition, REA and DDT score difference among age groups were larger for two-pair DDT than the one-paired. Two-pair DDT score showed a significant improvement with age for both ears, but the improvement was faster for the left ear [11].

In another study by Zenker et al. (2007), one, two and three-pair DDTs in free recall condition were used to examine age, ear, and task difficulty effects on the DDT score. They used 125 right-handed subjects aged 6 to 72 years and divided them into five age groups (6-11 years, 12-17 years, 18-33 years, 35-59 years, 60-72 years). The results showed a significant difference in two ears scores, age groups, and task difficulty. In all the age groups and three test types, REA was obvious, but it was more significant in the youngest and the oldest age groups. The harder the test, the larger was the REA. The results showed that maturation of corpus callosum makes dichotic processing more effective in middle-aged subjects as compared to the young children. In elderly, the dichotic processing is more like that in the young age [9].Moncrieff (2009) studied 217 subjects aged 10-28 years (11 left-handed, 200 righthanded, and 6 without any handedness).

They used DDT in free recall condition. The score improved with age, and this improvement was greater for the left ear. Both ears' score, especially left ear, showed a reduction in the score for task difficulty. Highest REA was seen in the 10 to 11-years-old age group [18]. Rosenberg (2011) examined two-pair DDT in 200 children aged 5 to 12 years. The score in both ears increased and REA decreased with age, but the decrement was not uniform [7]. Moncrieff (2011) conducted another study on 247 children aged 5 to 12 years and performed random DDT (one, two and three pairs DDT) in free recall condition. In younger children, REA was found to be larger. The ear advantage decreased significantly from 8 to 12 years old [1].

In the present study, there was no gender effect on the two paired DDT in free recall condition. This finding is in agreement with Bergen Dichotic Listening database that showed no gender effect on Dichotic consonant-vowel (CV) in 1018 (535 females and 483 males) subjects aged 6 to 88 years [19]. In addition to the language effects on neuropsychologic evaluations, Sommer et al. (2008) conducted a study to examine gender, handedness, and planum temporale asymmetry effects on ear advantage. They used dichotic listening tests and functional brain 
imaging. Planum temporale asymmetry had no significant difference between males and females as well as there was no gender difference in the case of dichotic hearing tests' results [20]. Moncrieff (2009) studied 217 subjects aged $10-28$ years ( 131 females and 86 males) and found no gender effect on DDT [18]. Moncrieff (2011) showed that there was a gender effect on random DDT in children aged 5-12 years, and males had a larger ear advantage. The reasons for this disagreement between the results of the present study and Moncrieff's study were the differences in sample size, handedness, and probable age range. Moncrieff used 147 subjects aged from 5 to 12 years old (129 males and 188 females). In the present study, 750 subjects aged 8-12 years (250 males and 500 females) were tested. In Moncrieff's study, 190 subjects were right-handed, 12 were left-handed, and 45 had none handedness, but in the present study, all the subjects were right-handed [1].

Finally, in the present study, the two-pair DDT had good test-retest reliability (higher than 0.84 in all age groups). Koomar and Cermal (1981) found that DDT test-re test reliability was $66-90 \%$ [21]. Harper et al. (2006) showed that DDT had a good reliability in preschool children, and parallel results were also drawn by Mukari et al. (2006) [22].

\section{Conclusion}

In this study, normative data for Persian version of two pair DDT in free recall condition has been obtained for 8 to 12 years old children. This normative data enables audiologists to use this CAPD test easily in clinical and research domain and interpret results with confidence. In this study, the Persian version of two pair DDT has shown high test-retest reliability and can be used for CAPD evaluation in 8-12 years old children. With normative data, conducting DDT on children and interpretation of results would be more reliable and valid.

\section{Acknowledgment}

This study is a part of audiology $\mathrm{PhD}$ thesis research (No. 892503003) at the University of Social Welfare and Rehabilitation Sciences. The authors are grateful to all participants in this study.

\section{Conflict of Interest}

The authors declared no conflict of interests.

\section{References}

[1] Moncrieff DW. Dichotic listening in children: Age-related change in direction and magnitude of ear advantage. Brain and Cognition. 2011; 76(2):316-22. doi: 10.1016/j. bandc.2011.03.013

[2] Jerger J, Musiek F. Report of the consensus conference on the diagnosis of auditory processing disorders in school-aged children. Journal of American Academy of Audiology. 2000; 11(9):467-74.

[3] Dawes P, Bishop D. Auditory processing disorder in relation to developmental disorders of language, communication and attention: A review and critique. International Journal of Language \& Communication Disorders. 2009; 44(4):440-65. doi: $10.1080 / 13682820902929073$

[4] Bellis TJ. Treatment of (Central) Auditory Processing Disorders. In: Valente M, Hosford-Dunn H, Roeser RJ, editors. Audiology Treatment. $2^{\text {th }}$ ed. New York: Thieme Medical Publishers; 2008, p. 271-92.

[5] Strouse A, Wilson RH. Stimulus length uncertainty with dichotic digit recognition. Journal of American Academy of Audiology. 1999; 10(4):219-29.

[6] Carter AS, Wilson RH. The effect of filtering and inter-digit interval on the recognition of dichotic digits. Journal of Rehabilitation Research and Development. 2000; 37(5):599-606. PMID: 11322158

[7] Rosenberg G. Development of local child norms for the Dichotic Digits Test. Florida Journal of Communication Disorders. 1998; 18:4-10.

[8] Mahdavi ME, Aghazadeh J, Tahaei AA, Heiran F, Baghban AA. [Persian randomized dichotic digits test: Development and dichotic listening performance in young adults (Persian)]. Audiology. 2015; 23(6):99-113.

[9] Rajabpour E, Hajiabolhasan F, Tahaei AA, Jalaei S. [Development of persian single dichotic digit test and its reliability in 7 to 9 year old male students (Persian)]. Audiology. 2014; 23(5):68-77.

[10] Musiek FE, Chermark GD. Handbook of (central) auditory processing disorders. $1^{\text {st }}$ ed. San Diego: Plural Publishing Inc; 2006.

[11] Mukari SZ, Keith RW, Tharpe AM, Johnson CD. Development and standardization of single and double dichotic digit tests in the Malay language. Interational Journal of Audiology. 2006; 45(6):344-52. doi: 10.1080/14992020600582174

[12] Fernandes MA, Smith ML, Logan W, Crawley A, McAndrews MP. Comparing language lateralization determined by dichotic listening and fMRI activation in frontal and temporal lobes in children with epilepsy. Brain and Language. 2006; 96(1):106-14. doi: 10.1016/j.bandl.2005.06.006

[13] Amiriani F, Tahaei AA, Kamali M. [Comparative evaluation of auditory attention in 7 to 9 year old learning disabled atudents (Persian)]. Audiology. 2011; 20(1):54-63.

[14] Jutras B, Mayer D, Joannette E, Carrier ME, Chenard G. Assessing the development of binaural integration ability with the French dichotic digit test: Ecoute dichotique de chiffres. American Journal of Audiology. 2012; 21(1):51-59. doi: 10.1044/1059-0889(2012/10-0040) 
[15] Pohl P, Grubmuller HG, Grubmuller R. Developmental changes in dichotic right ear advantage. Neuropediatrics. 1984; 15(3):139-44. doi: 10.1055/s-2008-1052357

[16] Lotfi Y, Talebi H, Mehrkian S, Khodaei MR, Faghihzadeh S. [Effect of cognitive and central auditory impairments on satisfaction of amplification in hearing impaired older adults (Persian)]. Iranian Journal of Ageing. 2013; 7(25):45-52.

[17] Schmithorst VJ, Farah R, Keith RW. Left ear advantage in speech related dichotic listening is not specific to auditory processing disorder in children: A machine-learning fMRI and DTI study. NeuroImage: Clinical. 2013; 3:8-17. doi: 10.1016/j.nicl.2013.06.016

[18] Moncrieff DW, Wilson RH. Recognition of randomly presented one-two-, and tree pair dichotic digits by children and young adults. Journal of the American Academy of Audiology. 2009; 20(1):58-70. doi: 10.3766/jaaa.20.1.6

[19] Hugdahl K. Dichotic listenig in the study of auditory laterality. In: Hugdahl K, Davidson RJ, editors. The Assymetrical Brain. Cambridge: MIT Press; 2004, p. 441-75.

[20] Jafari Z, Toufan R, Aghamollaei M, Malayeri S, Rahimzadeh Sh, Esmaili M. [Effects of handedness and gender on auditory attention in Bergen dichotic listening (Persian)]. Advanced in Cognitive Sceince. 2012; 14(3):51-62.

[21] Koomar JA, Cermak SA. Reliability of dichotic listening using two stimulus formats with normal and learning disabled children. American Journal of Occupational Therapy. 1981; 35(7):456-63. doi: 10.5014/ajot.35.7.456

[22] Harper LV, Kraft RH. Lateralization of receptive language in preschoolers: Test-retest reliability in a dichotic listening task. Developmental Psychology. 1986; 22(4):553-56. doi: 10.1037//0012-1649.22.4.553 